\title{
Modelica-Based Dynamic Modeling of a Solar-Powered Ground Source Heat Pump System: A Preliminary Case Study
}

\author{
Defeng Qian ${ }^{1} \quad$ Zheng O’Neill $^{1}$ \\ ${ }^{1}$ Department of Mechanical Engineering, the University of Alabama, Tuscaloosa, AL, the United States \\ dqian@crimson.ua.edu, zoneill@eng.ua.edu
}

\begin{abstract}
This paper presents preliminary simulation results from a Modelica - based dynamic model of a solar-powered ground source heat pump (GSHP) system. The model is calibrated and tested using the data collected from a test rig in the laboratory. The preliminary data collected from the test rig includes temperatures for water and air loops, solar heat radiation flux, solar panel output power, and power consumption of the GSHP. This preliminary study is focusing on the comparisons between Modelica model outputs and experimental data, which includes the power consumption of the GSHP unit, unit cooling capacity, and unit coefficient of performance (COP).
\end{abstract}

Keywords: $\quad$ Ground source heat pump, SolarPowered, Modelica

\section{Introduction and Background}

According to the recent research (Berardi, 2015), from 2007 to 2035, the global demand for oil will increase by $30 \%$, while the demand for coal and natural gas will increase by $50 \%$. Those data inform us that energyrelated carbon emissions will increase significantly if there are no radical changes in the energy structure. According to the annual energy outlook report, the building sector consumed $40 \%$ of the energy and $70 \%$ of the electricity in the U.S. in 2017. (EIA, 2017). About $24 \%$ of all energy used in the nation was for space heating, cooling, and water heating in the buildings (DOE, 2010). Besides the system safety and occupants' thermal comfort, improving energy efficiency and reducing energy consumption in buildings is one of the most important priorities during the operation stages of buildings.

Enhancing building efficiency is one of the simplest, most immediate and most cost-effective ways to reduce the carbon emissions ( $\mathrm{Li}$ and Colombier, 2009). In addition, integrating renewable energy sources into an efficient Heating, Ventilation, and Air-Conditioning (HVAC) would make a net-zero energy building (NZEB) possible. Theoretically, the goal of NZEB is to reduce the energy consumption (and demand) through efficient designs and operations, and utilize the renewable energy as a major energy source while the conventional energy sources play a backup role in the buildings. The key enablers for the NZEB include: 1) a highly efficient building envelope, 2) high-performance HVAC systems with the advanced control strategy, and 3) a balance between the building energy consumption and onsite power generation (Besant, Dumont et al., 1979, Hayter, Torcellini et al., 2000, Marszal, Heiselberg et al., 2011, Marszal, Heiselberg et al., 2012, Attia, Hamdy et al., 2013).

\subsection{Ground Source Heat Pump (GSHP)}

As one of the most efficient systems on the market, the GSHP system has been proved as one of the most energy-efficient solutions for the building HVAC system for a wide variety of geology conditions (ASHRAE, 2007). GSHP system combines the heat pump and a ground loop heat exchanger for transferring the heat between the building and the ground source.

Compared to the air-source heat pump that utilizes the environmental air as the heat source/sink, the GSHP utilizes the earth such as groundwater or soil as the heat source/sink. Since ground maintains at a relatively constant temperature over the year, the GSHP system is about $45 \%$ more efficient than conventional air source heat pumps (EnergyStar, 2018).

In general, open-loop system, closed-loop system, and semi-open-loop system are the most common design for the GSHP system. According to Huttrer (Huttrer, 1997), an open-loop system uses the groundwater directly. The groundwater passes through the heat pump unit and is discharged back to the source. In a closed-loop system, the water or the waterantifreeze solution circulates in a continuous buried pipe, which acts as a ground heat exchanger between the ground source and the circulating fluid. Compared to the closed-loop system, an open-loop system is inexpensive and efficient; however, additional maintenance is required to prevent fouling of loops by organic matter, etc. In addition, discharge of water from an open loop system to a surface waterbody may require a permit. In the U.S., Environmental Protection Agency (EPA) requires reporting any injection of the water to a return well for groundwater heat pump systems. The semiopen-loop system (i.e., standing column well system) combines the advantage of both open-loop system and closed-loop system. The focus of this study is an openloop GSHP system as shown in Figure 1. Due to the low $\mathrm{pH}$ value of the groundwater in the test location, a plate heat exchanger was introduced between the heat pump 
condenser and the groundwater loop to avoid the potential corrosion of the condenser.

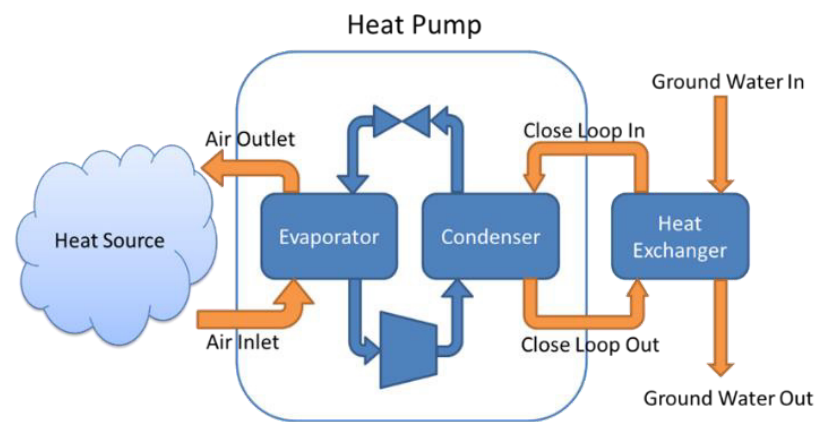

Figure 1. The open-loop GSHP system in this study

\subsection{Renewable/Sustainable Energy (Solar Energy)}

Growing population and technology evolutions caused the energy demand increased significantly in the past decades. Currently, as the primary source of the energy demand, fossil fuel shortage can be predicted while the energy demand is increasing continuously (PérezLombard, Ortiz et al., 2008, Shafiee and Topal, 2009). The fossil fuel is a type of finite resource and responsible for significant carbon emissions (Ediger, Hoşgör et al., 2007). Back in 2007, the World Energy Outlook predicted that $84 \%$ of the energy demand would depend on the fossil fuels in 2030 (Shafiee and Topal, 2009). This type of situation motivates people to explore an alternative way to satisfy the energy demand.

Meanwhile, renewable energy can be obtained from the natural sources, including solar, wind, biomass, etc. It is considered as an unlimited and environmentfriendly energy source (Twidell and Weir, 2015). As one of the most widely used renewable sources, solar energy has been widely used for solar thermal and solar power applications. It is not only a promising source but also abundant energy. Kannan and Vakeesan's recently did a review study about the solar energy and its future, and their study listed the situation, potential applications, and barriers to the solar industry. The study was a valuable reference for solar-related manufacturers, researchers, and decision-makers to take further actions (Kannan and Vakeesan, 2016). Figure 2 shows a map of global horizontal irradiation (GHI). The map shows the potential solar energy is at a range of 1,500 to 2,200 $\mathrm{kWh} / \mathrm{m}^{2}$ in the United States.

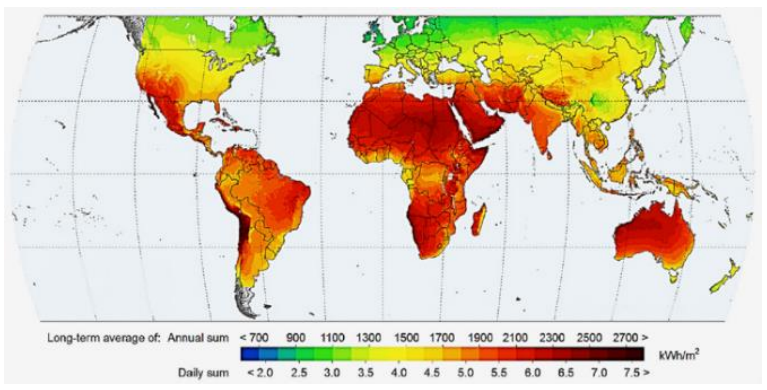

Figure 2. Maps of global horizontal irradiation (GHI) (Kannan and Vakeesan, 2016)

\subsection{Modeling with Modelica}

As the mathematical modeling and simulation became the key factors in engineering, computational tools were developed to satisfy the needs of efficient engineering. Modelica-based models (Modelica, 2018) complied using Dymola (Dymola, 2018) are used in this study. Modelica is an equation-based and object-oriented modeling language for complex multi-physics systems. The use of Modelica for the built environment is promising as buildings involve multiple physical phenomena (e.g., heat transfer, fluid dynamics, electricity, etc.) and are complex in terms of their dynamics (e.g., the coupling of continuous time physics with discrete time and discrete event control). In addition, the problem size can be varied from equipment to buildings and communities with electrical distribution grids. An advantage of Modelica is the modularity of the language that allows modification of the code according to the specific needs of the application. The object-orientation enables extension and reuse of components, and the use of standardized interfaces enables collaboration across physical domains and disparate developer groups. Modelica has been used to model the complex physical system, e.g., mechanical, electrical, electronic, hydraulic, thermal, control, electric power systems or process-oriented subcomponents (Modelica, 2018).

In general, a high-performance component and system could be less efficient without the appropriated and robust control strategies. Model-based control has been widely used in automobile, aerospace, and industry processes, and starts to emerge in the building industry. The dynamic modeling capability offered by Modelica provides a good framework for such model-based control design.

In this study, a Modelica-based dynamic model is developed to simulate the dynamics of solar-powered GSHP system. The commercial Modelica library Vapor Cycle library was adopted (Modelon, 2018) for steady-state and transient simulation of a refrigeration cycle in the ground source heat pump. It is compatible with some Modelica libraries such as Liquid Cooling Library, Heat Exchanger Library, etc. (Modelon, 2018).

This paper presents the simulation results from the Modelica model of the GSHP unit, together with comparisons between simulation results and measurements from a test rig. The performance analysis and comparisons were conducted for the cooling mode only since the test rig was only operated in such mode. Only modeling and validations of the heat pump component of the test rig are included in this paper. The performance comparison covers the power consumption of the heat pump unit, unit cooling capacity, and unit COP. 


\section{Methodology}

\subsection{Test Rig Physical System Setup}

As shown in Figure 3, a solar-powered GSHP system was the focus of this research to explore the benefits of integrating GSHP and the solar panels. In this test rig, a $3 / 4$-ton water-to-air GSHP is connected to two 60 -feet deep walls. A group of Solar PV panels of $1.12 \mathrm{~kW}$ is connected to two 800 Ah battery banks, which are used to power the GSHP system and a 270 Watts DC powered well pump. During the daytime, solar PV panels convert solar photons into electrical energy, which will be stored in battery banks. Whenever the system is on demand, the battery banks can provide the electrical power. Meanwhile, a comprehensive performance monitoring and data acquisition system is installed. Figure 4 shows the GSHP unit with measurement points. Table 1 lists the major sensors deployed in the test rig. A three-hour testing data is used in this study.

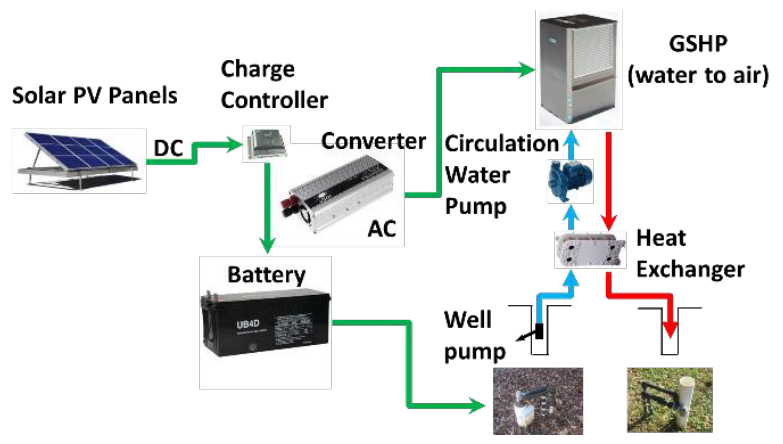

Figure 3. Overall system schematics of the studied solarpowered GSHP system

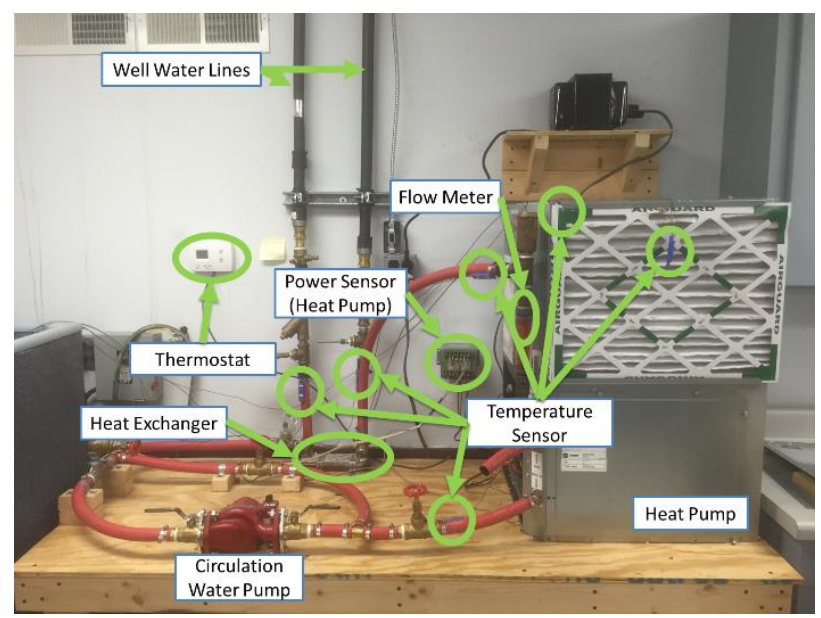

Figure 4. The heat pump unit with measurement points

A comprehensive performance monitoring and data acquisition system was installed (Figure 5). The data acquisition is combined with a chassis system which has five hybrid slots, three PXI Express slots (up to $250 \mathrm{MB} / \mathrm{s}$ per-slot bandwidth and $1.75 \mathrm{~GB} / \mathrm{s}$ system bandwidth) and two input modules. The thermocouple input module has 32-channel, eight built-in cold junction compensation channels and a $0.3{ }^{\circ} \mathrm{C}$ accuracy. The voltage module has 16 analog inputs, two analog outputs, 16-bit resolution and a range of $+10 \mathrm{~V}$.

Table 1. Major Sensors Deployed in the Test Rig

\begin{tabular}{|l|l|}
\hline Position & Sensor $^{*}$ \\
\hline $\begin{array}{l}\text { Ground Water Inlet (from } \\
\text { the well) }\end{array}$ & Temperature Sensor 1 \\
\hline $\begin{array}{l}\text { Ground Water Outlet (to } \\
\text { the well) }\end{array}$ & Temperature Sensor 2 \\
\hline $\begin{array}{l}\text { Circulate Water Inlet (to } \\
\text { the GSHP) }\end{array}$ & Temperature Sensor 3 \\
\hline $\begin{array}{l}\text { Circulate Water Outlet } \\
\text { (from the GSHP) }\end{array}$ & Temperature Sensor 4 \\
\hline Air Intake (to the GSHP) & Temperature Sensor 5 \\
\hline $\begin{array}{l}\text { Air Outlet (from the } \\
\text { GSHP) }\end{array}$ & Temperature Sensor 6 \\
\hline Power Sensor (GSHP) & Power Transducer \\
\hline Solar Panel Input Voltage & Voltage Divider \\
\hline Solar Panel Input Current & Current Shunt \\
\hline
\end{tabular}

*The temperature sensor is a T-type thermocouple.

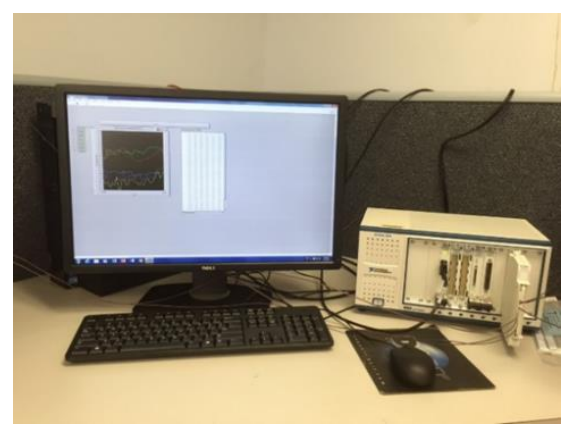

Figure 5. Data acquisition system in the test rig

\subsubsection{Supply Side}

The supply side for the studies system includes solar panels, battery banks, and a charge controller. Two sets of solar panels were used to charge the battery banks. The first set has 20 panels in two groups, and 16 of them were connected in four series loops (48 Volt). Each panel has a rated 50 Watts output. Thus, the total output from 16 panels would be 800 Watts. The second set has four panels with a rated output of 80 Watts per panel. The second set has a maximum output 320 Watts. However, since the first set was installed more than 20 years ago, a certain amount of performance degradation can be expected for these solar panels, while the second set is expected to operate close to the rated condition. Two battery banks are introduced as the energy storage devices, as one battery bank serves the GSHP, another one provides electricity to the well pumps in the system. Whenever the GSHP system is on demand, the battery banks will provide the electricity to maintain the system in operation. 


\subsubsection{Demand Side}

The demand side of the studied system includes a GSHP unit, a circulation pump, and well pumps. The heat pump adopted in this study has a rotary type compressor, rated cooling capacity is 2,638 Watts. The unit uses R$410 \mathrm{a}$ as the refrigerant, with charging weight of 0.751 $\mathrm{Kg}$. Under the normal operating condition, the refrigerant pressure is $3,103 \mathrm{kPa}$ at the condenser side, and $1,724 \mathrm{kPa}$ at the evaporator side. For the air side, the maximum external static pressure is $17,436 \mathrm{~Pa}$. The rated operating voltage is 208 Volts, and the shortcircuit current rating is $5 \mathrm{kA}$ at $600 \mathrm{~V}$.

\subsection{Modelica Model}

A Modelica - based dynamic model is used to study the behaviors of the GSHP system. Only the modeling of the GSHP unit is included in this paper. The GSHP unit component (e.g., compressor, condenser, evaporator, expansion valve) were modeled using the existing Modelica library-Vapor Cycle Library (Modelon, 2018). The initial conditions were adjusted based on the test conditions and the manufacturer's specifications. The working fluid in the studied GSHP is R410a, and the secondary side fluid is water at the condenser side and air at the evaporator side. The well is not directly modeled in this paper, heat source and heat sink with constant temperatures was specified using the data from measurements. More details of this assumption are provided in the next section.

Simulation models were created and compiled by using the multi-engineering dynamic simulation tool Dymola (version 2017 FD01) (Dymola, 2018). Table 2 lists the major components used in this model.

Figure 6 shows the Dyamloa model of the studied GSHP unit. System status data such as the power consumption of the compressor, heating/cooling rate, and the COP are pulled out and can be directly read from the main panel.

Table 2. Major Components in the Modelica model

\begin{tabular}{|l|l|}
\hline Component & Model Descriptions \\
\hline Condenser & Heat exchanger; \\
& Counterflow; \\
& R410a as working fluid; \\
& Water as liquid \\
\hline Evaporator & $\begin{array}{l}\text { Heat exchanger; } \\
\text { Counterflow; }\end{array}$ \\
& $\begin{array}{l}\text { R410a as working fluid; } \\
\text { Air as liquid }\end{array}$ \\
\hline Expansion Valve & $\begin{array}{l}\text { Simplified Thermal } \\
\text { Expansion Valve model, } \\
\text { based on compressible flow } \\
\text { valve in IEC 534/ISA S.75 } \\
\text { standards }\end{array}$ \\
\hline Compressor & $\begin{array}{l}\text { Fixed displacement } \\
\text { compressor with speed and } \\
\text { pressure ratio dependency }\end{array}$ \\
\hline
\end{tabular}

\begin{tabular}{|l|l|}
\hline Liquid Source & $\begin{array}{l}\text { Modelon.Media.PreDefined.L } \\
\text { iquids.IncompressibleWater is } \\
\text { the Medium on condenser } \\
\text { side; } \\
\text { VaporCycle.Media.Air.Moist } \\
\text { AirNoFreezing is the medium } \\
\text { on evaporator side. }\end{array}$ \\
\hline Liquid Sink & $\begin{array}{l}\text { Modelon.Media.PreDefined.L } \\
\text { iquids.IncompressibleWater is } \\
\text { the Medium on condenser } \\
\text { side; } \\
\text { VaporCycle.Media.Air.Moist } \\
\text { AirNoFreezing is the medium } \\
\text { on evaporator side. }\end{array}$ \\
\hline
\end{tabular}

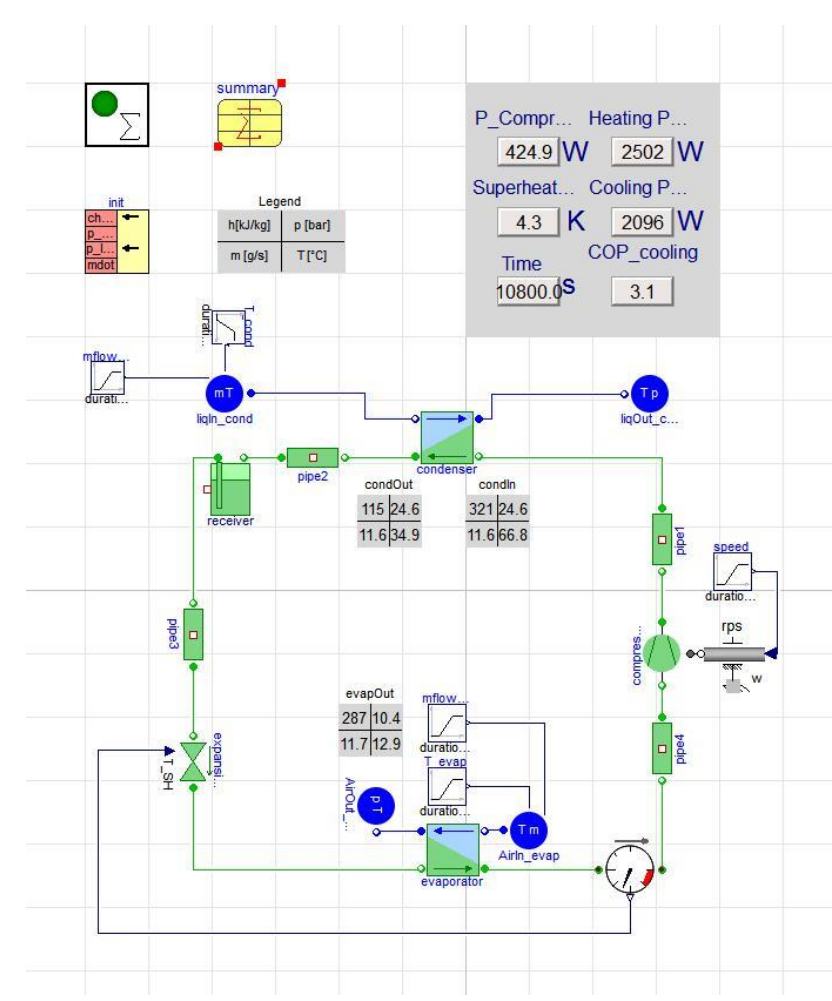

Figure 6. A Dymola model of the GSHP unit

\subsubsection{Assumptions of the current Modelica model of GSHP unit}

In this preliminary study, the following assumptions are used:

1. Constant temperatures were used in the Modelica model for the heat sink (i.e., the water inlet temperature on the condenser side) and the heat source (i.e., the air inlet temperature on the evaporator side). This assumption is a close approximation as observed from the actual testing data. Figure 7 shows that both the water inlet temperature and the air inlet temperature were relatively constant after the system went into the steady state (roughly $20^{\circ} \mathrm{C}$ and $22{ }^{\circ} \mathrm{C}$ respectively).

2. The current Modelica model didn't include the blower fan, which is another major component 
of the GSHP unit in the test rig. The current test rig only measured the total power consumption of the GSHP unit, which is the sum of the power consumption of the compressor and the fan. To have a fair comparison between the measurements and the model predictions, in this paper, a constant fan power consumption was assumed to get the total power consumption of the GHSP unit from the Modelica model.

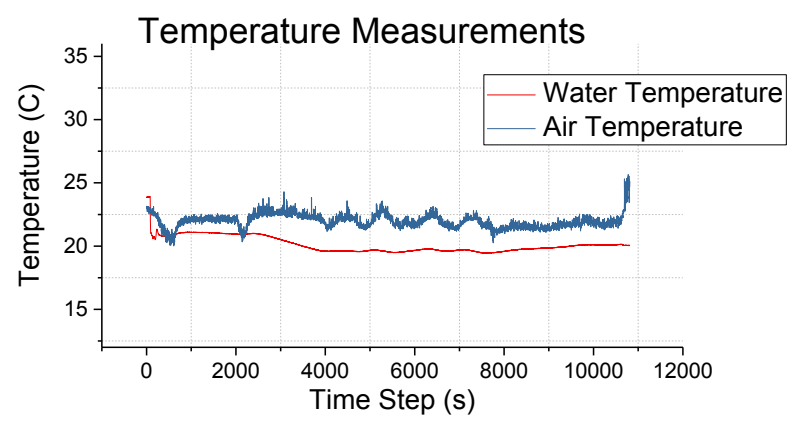

Figure 7. Water inlet and air inlet temperatures from measurements

\subsection{System Performance Analysis}

\subsubsection{The Coefficient of Performance (COP)}

The COP is a dimensionless parameter which is used to measure the efficiency of the heat pump. A higher value of COP corresponds to the better performance of the heat pump. In this study, the COP of the GSHP unit was calculated by using the following equation:

$$
C O P_{H P}=\frac{q_{\text {cooling }}}{P_{H P}}
$$

Where $C O P_{H P}$ is the COP of the heat pump; $q_{\text {cooling }}$ is the cooling capacity (W); $P_{H P}$ is the power consumption of the heat pump (W).

In a heat pump unit, there are multiple components consumes electrical energy during the operation. This study assumes only the compressor and the blower fan consume the energy, while the energy consumptions from other components are negligible during the operation. Therefore, the power consumption for the GSHP unit is defined as follow:

$$
P_{H P}=P_{\text {compressor }}+P_{\text {fan }}
$$

Where $P_{\text {compressor }}$ is the power consumption of the compressor $(\mathrm{W}) ; P_{f a n}$ is the rated power for the blower fan $(\mathrm{W})$. Currently, only $P_{H P}$ is measured in the test rig.

\subsubsection{Heat Pump Energy Balance}

The energy balance on the heat pump represents the system performance in either the cooling or heating mode. The energy balance is based on the energy consumption of the heat pump, the heat exchange rate between the water-side and airside of the heat pump, and the cooling or heating rate of the heat pump. In this paper, all the tests were conducted for the cooling mode. The following equation is used to calculate the cooling rate and check the total energy balance (Qian, Niu et al., 2016):

$$
P_{H P}+q_{r e j}+q_{\text {cooling }}=0
$$

Where $q_{\text {rej }}$ is the heat rejection rate (W) from the heat pump to the water loop; $q_{\text {cooling }}$ is the cooling capacity (W) of the GSHP unit.

\subsubsection{Heat Rejection}

The heat rejection of a water-to-air heat pump counts the energy transfer from the air to the water loop. In this study, the heat rejection rate was calculated according to the flow rate of the circulation groundwater and temperature difference of the circulation groundwater loop. Equation (4) is used to calculate the heat rejection of the GSHP unit in this study:

$$
q_{\text {rej }}=\dot{m}_{\text {water }} \times C_{p} \times \Delta T_{C L}
$$

Where $\dot{m}_{\text {water }}$ is the mass flow rate $(\mathrm{kg} / \mathrm{s})$ of the circulating groundwater; $C_{p}$ is the specific heat of water $(\mathrm{J} / \mathrm{kg}-\mathrm{K}) ; \Delta T_{C L}$ is the temperature difference $(\mathrm{K})$ between the condenser water inlet and outlet of the heat pump unit. This temperature difference is measured in the test rig.

\subsubsection{Measure of Goodness}

Statistic performance metrics help to determine how well a model can predict the performance of the system compared to the measurements. In this study, the coefficient of variation of the root mean square error (CVRMSE) and normalized mean bias error (NMBE) were used to determine the model accuracy (ASHRAE, 2002).

Root mean square error (RMSE) is a frequently used metric to measure the errors between model predictions and actual measurements, s shown in Equation 5:

$$
R M S E=\sqrt{\frac{\sum\left(y_{a c t}-y_{\text {mod }}\right)^{2}}{(n-p)}}
$$

CVRMSE is the coefficient of variation of the root mean square error, as shown in Equation 6.

$$
C V R M S E=\frac{R M S E}{\bar{y}_{a c t}} \times 100 \%
$$

NMBE is the ratio of the differences between actual measurements and simulated results to the degrees of freedom and mean value of the actual measurement.

$$
N M B E=\frac{\sum\left(y_{a c t}-y_{m o d}\right)}{(n-p) \times \bar{y}_{a c t}} \times 100 \%
$$

Where $y_{a c t}$ and $y_{\text {mod }}$ are the actual measured and model predicted result; $\bar{y}_{a c t}$ is the average of the actual measured data; $n$ is the number of observation; $p$ is the number of parameters in the regression model.

\section{Results and Discussions}

After the Modelica model was developed, a data set which was collected from the test rig was used to test 
and evaluate the accuracy of the model. The Modelica model was built and simulated under the same operating conditions of the testing. The testing condition was as follows:

1) The comparisons between the actual measurements and simulation results were based on a three-hour testing.

2) The GSHP system was operating in a cooling mode.

3) The environment temperature was controlled at $22{ }^{\circ} \mathrm{C}$, while the discharge air temperature set point of the GSHP system was $16{ }^{\circ} \mathrm{C}$. The GSHP system maintained in operation during the three-hour test.

4) The flow rate of circulation groundwater was measured at $0.454 \mathrm{~m}^{3} / \mathrm{hr}$, while the air flow rate was maintained at $0.134 \mathrm{~m}^{3} / \mathrm{sec}$.

5) The measured temperature values include inlet water temperature at the condenser side and inlet air temperature at the evaporators side was used as the inputs to the Modelica model.

6) Other settings were referred to the manufacturer's specifications.

\subsection{Power Consumption of the GSHP Unit}

In the testing setup, the compressor is one of the major energy consumers in the system, the energy consumption of the compressor determines the performance of the GSHP system. Meanwhile, the testing unit was operating as a fixed air flow rate, the power consumption of the blower fan was assumed to operate in a rated condition (248 Watts) in this paper for the simplicity.

Figure 8 shows a comparison of the unit power comparison. After the system reached a steady state, the actual measurement was about 600 Watts, while the simulated power consumption of the unit was averaged at 670 Watts. The difference for the average power consumption during the three-hour testing period was approximately $11.67 \%$.

\section{Power Consumption Comparison}

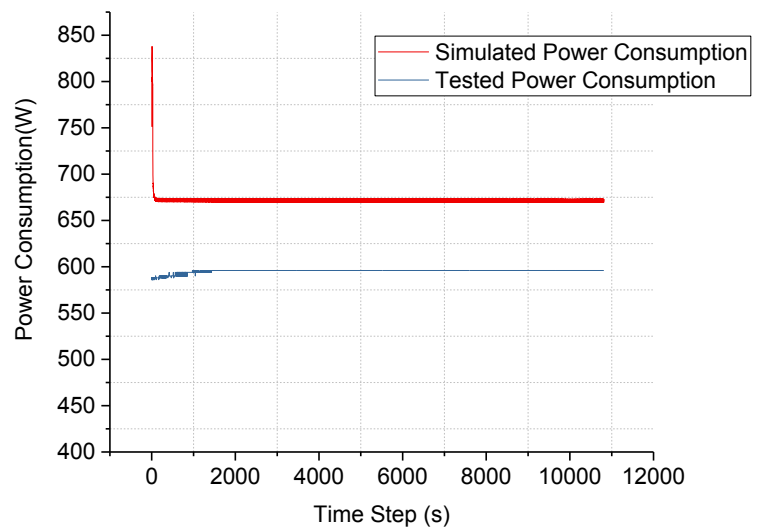

Figure 8. Comparisons of power consumption of the GSHP unit
As mentioned in section 2.2.1, a constant fan power consumption was assumed to get the total power consumption of the GHSP unit in the Modelica model since the fan was not included in the model. However, the fan power consumption most likely will not be maintained at the rated condition during the testing. This could explain why the simulated unit power consumption was consistently larger than the measurements. A fan model will be included into the Modelica model, and an additional measurement point for actual fan power consumption will be added as well.

\subsection{Cooling Capacity}

As mentioned in the previous section, the testing unit was a $3 / 4$-ton water-to-air GSHP system, which has a rated cooling capacity at 2,638 Watts. The actual cooling capacity was calculated by using Equation 3 in this paper.

Figure 9 shows the comparisons of the measured and simulated cooling capacity. According to the testing result, the actual cooling rate was maintained around 2,300 Watts after the system went into a steady state. As the simulation result was around 2,100 Watts, there was roughly $8.69 \%$ difference for the average cooling capacity between the test measurement and the simulation result.

In the current test rig, although the indoor air temperature was controlled and measured, the humidity in the lab was not controlled and measured. The moist air medium used in the Modelica model probably has the different humidity ratio compared to actual conditions in the test rig. This certainly would cause a different latent load between the simulation and the test cases. Theoretically speaking, more moist air could lead to a larger latent load for the heat pump unit, then result in a higher cooling capacity.

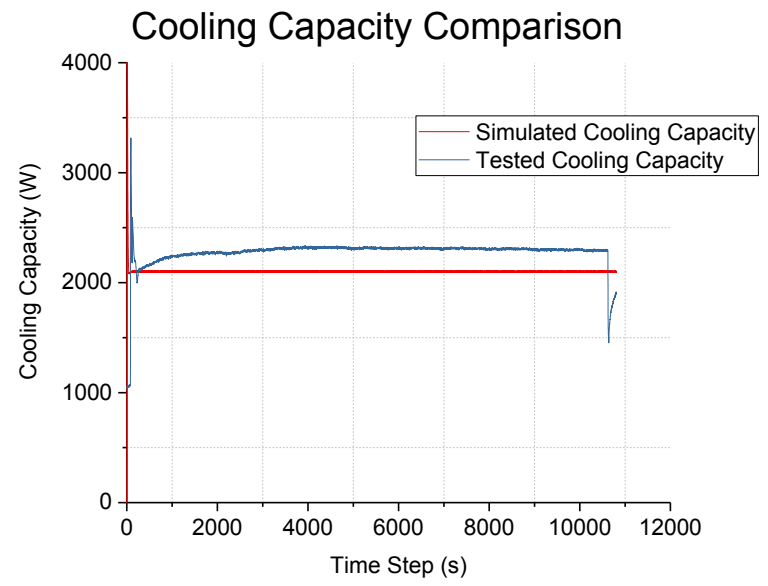

Figure 9. Comparisons of the GSHP unit cooling capacity

\subsection{COP}

The testing rig was operating under the cooling mode, only the cooling COP is discussed in this paper. The cooling COP from the testing was calculated using Equation 1. 
Figure 10 shows the comparisons of the cooling COP for the three-hour testing period. After the test went into a steady state, the measured COP was about 3.8, while the simulation result was around 3.2. The comparison indicated $15.79 \%$ difference on mean on the COP.

As shown in the previous sections, actual test measurements indicate a higher cooling capacity and a lower power consumption Thus, the COP from the testing was higher compared to the simulated COP from the Modelica model.

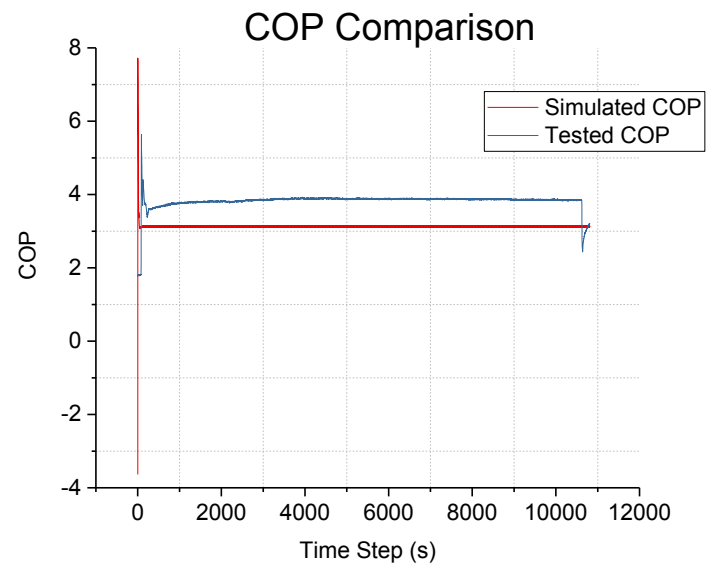

Figure 10. Cooling COP during the simulation.

\subsection{Model Evaluation Metrics}

Table 3 shows the measures of goodness for the model accuracy in this study. The CVRMSE were around 12.29\%, $12.92 \%$, and $19.69 \%$ for power consumption, cooling capacity, and COP respectively. The NMBE for these three outputs was $12.85 \%, 7.42 \%$, and $17.98 \%$ respectively.

Table 3. Performance evaluation of the Modelica model

\begin{tabular}{|l|c|c|}
\hline \multicolumn{1}{|c|}{ Category } & CVRMSE & NMBE \\
\hline $\begin{array}{l}\text { Power } \\
\text { Consumption }\end{array}$ & $12.92 \%$ & $12.86 \%$ \\
\hline Cooling Capacity & $12.29 \%$ & $7.42 \%$ \\
\hline COP & $19.69 \%$ & $17.99 \%$ \\
\hline
\end{tabular}

\section{Conclusions and Future Work}

This study presents the preliminary results from the Modelica-based modeling of a GSHP unit. The model predictions were compared with measurements from the test rig. The current Modelica-based model can simulate the performances of the GSHP unit. The output trends for the Modelica simulation match with those from measurements well.

This Modelica model will be extended to a full scale of the solar-powered GSHP system that includes solar panels, battery banks, charge controller, and groundwater wells. Some of the ongoing and future work are listed as follows:

1) Modelica model of the supply side of solar panels, which will use the actual weather data as the input to estimate the power generation of the solar panels.

2) On the groundwater side, a Modelica model of the groundwater well will be developed so the impact of ground (e.g., thermal conductivity and hydraulic conductivity) can be further analyzed.

3) A comprehensive system model of solarpowered ground source heat pump system will be validated using the measurement from the test rig. Testing data will be collected for a longer period for both heating and cooling modes.

4) Dynamic inputs such as weather information, room air and groundwater temperature profiles will be used as inputs in the full scaled model to study the dynamic performance of the system.

5) After the system model is developed and validated, this dynamic model will be used for the following applications:

- Model-based control of the solar power generation system and ground source heat pump system, and the combination of these systems for a better building to grid integration.

- Local heat pump controller design using this dynamic model in the Hardware-in-the-loop testing.

\section{Nomenclature}

ASHRAE: American Society of Heating, Refrigerating and Air-Conditioning Engineers

COP: Coefficient of Performance

CVRMSE: coefficient of variation of the root mean square error

EPA: Environmental Protection Agency

GHI: global horizontal irradiation

GSHP: Ground Source Heat Pump

HVAC: Heating, Ventilation, and Air-Conditioning

NZEB: Net Zero Energy Building

NMBE: normalized mean bias error

RMSE: Root mean square error

\section{References}

ASHRAE (2002). "ASHRAE guideline 14-2002. Measurement of energy and demand savings." American Society of Heating, Refrigerating and Air-Conditioning Engineers, Inc., Atlanta, GA.

ASHRAE (2007). "HVAC Applications Handbook." American Society of Heating, Refrigerating and AirConditioning Engineers, Inc., Atlanta, GA.

Attia, S., M. Hamdy, W. O’Brien and S. Carlucci (2013). "Assessing gaps and needs for integrating building performance optimization tools in net zero energy buildings design." Energy and Buildings, 60: 110-124.

Berardi, U. (2015). "Building energy consumption in US, EU, and BRIC countries." Procedia Engineering, 118: 128-136.

Besant, R. W., R. S. Dumont and G. Schoenau (1979). "The Saskatchewan conservation house: some preliminary performance results." Energy and Buildings, 2(2): 163-174. 
DOE (2010). Buildings Energy Data Book, 2011.

Dymola (2018). "DYMOLA Systems Engineering." from https://www.3ds.com/productsservices/catia/products/dymola/.

Ediger, V. Ş., E. Hoşgör, A. N. Sürmeli and H. Tatlıdil (2007). "Fossil fuel sustainability index: An application of resource management." Energy Policy, 35(5): 2969-2977.

EIA (2017). Annual Energy Outlook, U.S. Energy Information Administration. U. S. Department of Energy.

EnergyStar (2018). "Geothermal Heat Pumps." from https://www.energystar.gov/products/heating_cooling/heat _pumps_geothermal.

Hayter, S., P. Torcellini, R. B. Hayter and R. Judkoff (2001). The energy design process for designing and constructing high-performance buildings, Clima 2000/Napoli 2001 World Congress.

Huttrer, G. W. (1997). "Geothermal heat pumps: an increasingly successful technology." Renewable Energy, 10(2-3): 481-488.

Kannan, N. and D. Vakeesan (2016). "Solar energy for future world:-A review." Renewable and Sustainable Energy Reviews, 62: 1092-1105.

Li, J. and M. Colombier (2009). "Managing carbon emissions in China through building energy efficiency." Journal of Environmental Management, 90(8): 2436-2447.

Marszal, A. J., P. Heiselberg, J. S. Bourrelle, E. Musall, K. Voss, I. Sartori and A. Napolitano (2011). "Zero Energy Building-A review of definitions and calculation methodologies." Energy and Buildings, 43(4): 971-979.

Marszal, A. J., P. Heiselberg, R. L. Jensen and J. Nørgaard (2012). "On-site or off-site renewable energy supply options? Life cycle cost analysis of a Net Zero Energy Building in Denmark." Renewable Energy, 44: 154-165.

Modelica (2018). "Modelica and the Modelica Association." from https://www.modelica.org/.

Modelon (2018). "Vapor Cycle Library." from http://www.modelon.com/products/modelon-librarysuite/vapor-cycle-library.

Pérez-Lombard, L., J. Ortiz and C. Pout (2008). "A review on buildings energy consumption information." Energy and Buildings, 40(3): 394-398.

Qian, D., F. Niu, S. Kavanaugh and Z. O'Neill (2016). "Investigation on A Ground Source Heat Pump System Integrated With Renewable Sources." International Compressor Engineering, Refrigeration and Air Conditioning, and High Performance Buildings Conferences. West Lafayette, IN. July 11 - 14, 2016.

Shafiee, S. and E. Topal (2009). "When will fossil fuel reserves be diminished?" Energy Policy 37(1): 181-189.

Twidell, J. and T. Weir (2015). Renewable energy resources, Routledge. 